\title{
The Performance of Knowledge: Pointing and Knowledge in Powerpoint Presentations
}

\author{
1 Hubert Knoblauch \\ Technical University of Berlin
}

\begin{abstract}
Powerpoint and similar technologies have contributed to a profound transformation of lecturing and presenting information. In focusing on pointing in powerpoint presentations, the article addresses aspects of this transformation of speech into 'presentations'. As opposed to popular attacks against powerpoint, the analysis of a large number of audio-visually recorded presentations (mainly in German) demonstrates the creativity of these 'performances', based on the interplay of slides (and other aspects of this technology), speech, pointing and body formations. Pointing seems to be a particular feature of this kind of presentation, allowing knowledge to be located in space. Considering powerpoint as one of the typical technologies of so-called 'knowledge societies', this aspect provides some indication as to the social understanding of knowledge. Instead of 'representing' reality, knowledge is defined by the circularity of speaking and showing, thus becoming presented knowledge rather than representing knowledge.
\end{abstract}

\section{KEY WORDS}

communication / communicative culture / knowledge / knowledge society / performance / performative / powerpoint

\section{Introduction: Powerpoint Makes You Dumb?}

ithin the last decade or so, powerpoint has become a technology and medium of communication that has disseminated at a speed one could call sensational. The number of social scientific studies of powerpoint and similar technologies, however, is surprisingly few, and most often they are either 
based on speculation or on the quantitative standardized analysis of learning effects with this technology. Some studies, though, deserve mentioning both because they have gained a certain amount of publicity, and also because they have taken a markedly critical, one may even say polemical, stance towards this technology. The work of the information scientist Tufte (2003) may be considered as epitomizing this type of critique. In his view, powerpoint must be accused of impoverishing the process of information dissemination. As an example, he argues that the catastrophe of the NASA space shuttle Columbia can be explained by the fact that, although the information relevant to the prevention of the accident was available, powerpoint did not allow the effective transmission of this information due to its inbuilt under-complexity. In addition to impoverishing the transmission of information, Tufte decries the fragmentation of thinking, the reduction of the potential to reflect, and the information overload ('death by powerpoint') caused by it - arguments that have been widely debated elsewhere.

Popular as these arguments have become, little is known about the factual use of this technology. For this reason, we started to study powerpoint and similar forms of audio-visually supported presentations in a research project initiated in $2005 .{ }^{1}$ The goal of this research project was the investigation of how the factual use of powerpoint affects the speech situation in presentations. That is, we do not restrict our data collection and analysis to the consideration of slides or software only (although we do analyse the types of slides used in real-time presentations). Instead, we focus on the performance of speakers and audiences while carrying out and participating in powerpoint presentations.

By the notion of 'performance', we want to stress that culture, communication, and meaning cannot be reduced to signs and sign systems. Reality is not given by signs; as a meaningful reality, it is instead created in action. In this sense we agree with Butler (1988) and Alexander et al. (2006) who consider those actions as performative that can be understood as communicating meaning. In this sense, performance can be called communicative action if one does not reduce this notion to communicative rationality, as Habermas (1981) has done. Instead, communicative action always involves a stock of more or less structured habitualized knowledges (Knoblauch, 2001). Whereas the latter may be referred to as communicative practice, the structures created by communicative actions will be referred to here as the communicative genre (Knoblauch and Günthner, 1995). The notion of performance also stresses the fact that communicative action is to be considered as a situational process in socially mediated time and space that contributes to the creation of meaning. In fact, performance studies stress that the process of communication in situations exhibits an order of its own, an order that consists not only of signs (as structuralists would argue) but also of their practical bodily and temporal enactment and reaction in social contexts. As will be seen with respect to pointing, actors perform in orderly ways that are culturally patterned, and it is these cultural patterns of performance that are the subject of the analysis that follows. 
This means that technically supported presentations cannot be reduced to the slides or texts and visualizations only. Rather, these presentations are here considered as enactments in which speech and images are interrelated with technology and media. Speech, texts, and slides are embedded in the use of technologies, such as notebooks, beamers, laser pointers, and presentation software; and these technologies allow for a mixture of written texts, visual projections and bodily modes of communication. From the perspective of the ethnography of communication (Bauman and Briggs, 1990; Hymes, 1974), presentations are performances that, rather than being mere 'speech' events, must be considered as communicative events. These events are characterized not only by the bodily and spoken performance and the activities of audiences. The presentation also includes 'mediated' elements, such as slides, paper copies of slides, written text or notes, and 'live forms', such as speech in front of a 'live audience' which is integrated to such a degree as to constitute a genre of its own: the 'presentation'. ${ }^{2}$ Thus the powerpoint presentation constitutes what may be called a 'hybrid' form consisting of both immediate interaction as well as technologically mediated action.

Against this background, we may first ask what determines the form of these presentations (i.e. the communicative genre). In order to do so, I will focus on a specific aspect of this genre, namely pointing, because it seems (a) most specific to the genre and (b) relates to various other aspects of the genre, most importantly the often ignored role of the human body in speech on the one hand, and its connection to technologies on the other. The dissemination of mediated technologies raises additional questions as to the cultural signification of the use of these technological media: do new technologies lead to a " technological and aesthetic contamination" of live performance' (Auslander, 1999: 40ff.)? Or could one consider them as an 'informization' of speech, that is, as the extension of the 'information society' (or 'knowledge society') into immediate, concrete settings? ${ }^{3}$

The data I will refer to consist of field records, interviews, and, in particular, videotaped records of presentations, focusing on speakers, slides, and audiences. (In many cases the research team also received digital copies of the slides.) The presentations have been recorded in 'natural situations', that is, as part of the routine practical activities of organizations. The organizations where we have carried out field research range from universities and research organizations (in different disciplines such as law, social sciences, natural sciences, and medicine) to administrations, private businesses, churches, and entertainment organizations. Types of occasion sampled vary from seminars, meetings and workshops to conferences, both national and international. In addition, we have collected data from presentations using different technologies, such as software-supported presentations using beamers, overhead presentations and flip-chart presentations, as well as seminars using blackboards. The corpus of data now consists of more than 200 presentations, lasting from two minutes up to two hours. The data have been analysed according to a method we call genre analysis (Knoblauch and Luckmann, 2004). This method is based on focused ethnography, sequence analysis as suggested by conversation analysis (Heath and Hindmarsh, 2002), and videography (Knoblauch, 2006). 
In the first part of this article, I will identify some forms and functions of pointing during powerpoint presentations that are embedded in other forms of bodily activities. It will be shown that pointing works as a kind of pivot, relating the body of the presenter, audiences, and the technologically visualized text. In turning to 'pointing of the second degree', I will then indicate some additional means to relate speech, speaker, audience, and presentations. Having established the various forms of pointing, I will then consider the cultural and social significance of powerpoint presentations. Based on the assumption that powerpoint presentations epitomize communication in the 'knowledge society', I will argue that they contribute to a substantial transformation of knowledge that is captured in the notion of the performance of knowledge.

\section{Forms and Functions of Pointing in Powerpoint Presentations}

When talking about pointing we should not restrict ourselves to language and linguistic deixis, which is often addressed in studies of oratory and spoken language. ${ }^{4}$ Pointing here refers to body and gesture deixis which may - or, as we will see, may not - be accompanied by linguistic deixis. Because pointing typically occurs within interaction (someone shows something to someone), it exhibits distinctive social characteristics. ${ }^{5}$ Pointing belongs to those forms of routinized practices actors are able to perform without necessarily having explicit knowledge about when and how they execute this action.

For this reason, the meaning of pointing has to be reconstructed in other ways. In gesture studies, one assumes that the meaning of gestures can be reconstructed by identifying the particular gestural forms that 'carry' meaning. On these grounds, pointing can be distinguished from, for example, iconographic gestures that appeal to visual images, or from mimetic gestures that mimic other processes. ${ }^{6}$ Indeed, if we look at the data in Figure 1, we can easily detect the use of different forms of pointing. Most popular, of course, is pointing with the index finger. In addition, pointing may be done with the palm downwards (Example 1), the hand forming a triangle (Example 2), or the hand forming an L-shape (Example 3).

The institutional importance of pointing becomes visible in the fact that, in addition to the hand, a series of technical instruments is available to support pointing: sticks, pens and pencils may be used as well as the computer mouse (although we find that presenters hardly ever utilize the mouse-pointing functions). The most popular form of pointing in connection with powerpoint is the use of the laser pointer. If in the analysis of pointing one also includes pointing by means of technical aids, one may observe that the signification of pointing is not dependent on the sign itself, as gesture studies suggest. Rather, the meaning of pointing is established in relation to other aspects of communication. Consider for example the following case taken from an academic powerpoint presentation with an audience of some 40 persons. ${ }^{7}$ The orator speaks and points (double underlined) (see the end of the article for transcription conventions): 

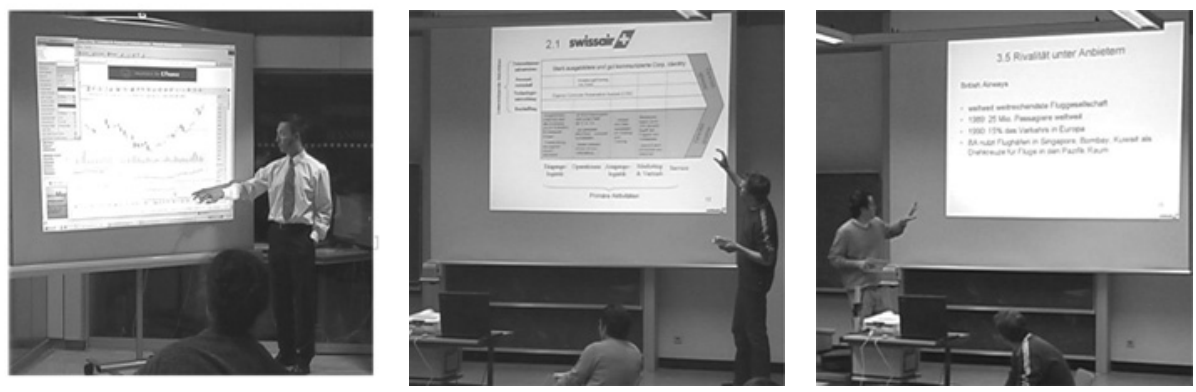

Figure I Types of pointing

1 wir ham dann sehr intensive Kart*ierung gemacht? und (-) man sieht eigentlich in Räumen we have done very intensive cartography? and (-) one actually sees in areas

2 wie dem Aach"eeraum $\mathrm{O} *$ st der sehr $\mathrm{z}^{*}$ entrumsnah ist; in dem die Stadtplanung eigentlich

like the Thames region east which is very close to the centre; in which city-planning

3 so 'n zweiten Münchner Pl" atz äh vorsieht; dass d"as; absolut vit*ale Räume sind für n

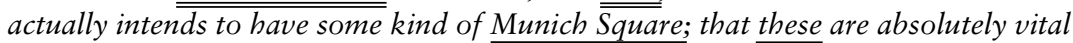

4 ganz äh großes unterschiedliches Spektrum ähm $\mathrm{n}$ groß $\overline{\overline{ß e s ~ S}}$ pektrum an unterschiedlichen

spaces for erm a large spectrum erm a large spectrum of different

5 Nutzungen. (3.3)

usages. (3.3)

The underlined text indicates that the speaker uses a pointing gesture at three points. Note that only at one of these points is the gesture in fact linked with a deictic pronoun (line 3). The first two gestures (lines 1 and 2) are pointings with the forehand which are linked to a movement of the arm resembling a wiping gesture. In line 3 ('these') we encounter a typical pointing gesture with palm downwards. In addition, there is a discursive gesture that does not point but follows the linguistic stress ('Pl*atz'). ${ }^{8}$ Although pointing often occurs without a linguistic deixis, it takes on specific meaning which in this example also derives from the context, such as localizations. Thus the difference between the deictic and the discursive gesture (that only functions as a stress to the spoken word) only becomes relevant by the tight coordination between the gestural form on the one hand, and the communicative context on the other hand, that is, the temporal coordination of the gesture and (as can be seen here) the speech (i.e. the references to locality such as 'Thames region' or 'Munich Square'). Yet already the reference of 'intensive cartography' (line 1) indicates that it is not only speech that provides the meaning-bestowing context for gestures, but also the visual elements of the presentation too. 
In order to demonstrate how pointing gesture, speech and the visual are interrelated in and by communicative action (and thus constituting the context for one another), we may turn to another example. Here, pointing is done by means of a laser pointer that can be considered the most elementary form of pointing. ${ }^{9}$ The extract stems from a powerpoint presentation in front of 20 listeners during an information meeting in a public administration organization (passages of talk during which the speaker is pointing with the laser pointer are double underlined):

1 ähm das ist jetzt so die:: klassische (-) Ausrüstung die einem zur Verfügung erm this is now like the classical (-) equipment which is available

2 steht wenn man eben Reis untersuchen möchte, ( ${ }^{\circ}$ sie sehen hier) if one wants to examine rice.. ${ }^{\circ}$ (You may see here)

3 auf der rechten Seite eben sone ${ }^{\circ}$ äh "Lupe die ${ }^{\circ}$ dazu $=$ dient ${ }^{\circ}$

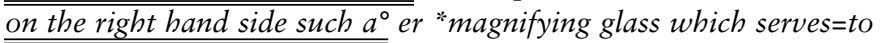

4 in die (-) Reiskörner oder unter der man die (-) Reiskörner halt entsprechend in the (-) rice grains or under which one may $p u t$ the (-) rice grains accordingly

5 auslegen kann=also=zum einen ebn=diese äh zweihundert ganzen Reiskörner

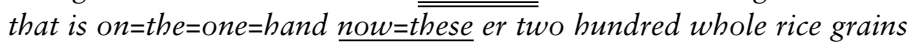

6 die man für die Untersuchung *braucht um eben die=Längen=und= that one needs for this investigation in order to determine the=length=and

7 Breitenverhältnisse feststellen zu können und dann links daneben (-) eben breadth and then aside on the left (-) now

8 jetzt die *Messuhr die wir als Referenzverfahren .hh ähm verwenden und zwar the micrometer screw which we use as a reference procedure namely because

9 aus dem Grund weil das eben ähm ein- eine geeichte Messuhr ist this is now erm a dial gange.

As in the earlier excerpt, the speaker uses the laser pointer in coordination with certain passages of his talk which thereby are made decipherable - they are illustrated by what he points at. Moreover, he not only points at certain elements; he is moving the pointer. One should not mistake these movements as involuntary tremblings of the hand. Rather, the movements of the laser pointer can be understood as interpretations of what the speaker is saying and what he is hinting at. This becomes very clear if one looks at these movements in more detail.

As can be seen on the copies of the slides and the lines imitating the movements of the laser pointer (see Figure 2), the speaker not only points to the slide, he 'circumscribes' certain units: the rice, the magnifying glass and the micrometer screw. Indeed, in circumscribing different items on the slide, he creates a distinction that parallels what he says in his talk. Verbally, he is producing a spatial contrast between right (line 3) and left (line 7). The distinction in pointing and the contrast in speaking are synchronized in time so that they are perceived as relating to the same thing: the magnifying glass on the right side (including some rice grains lying below it) and the dial gauge on the left side. Moreover, the duality of the structure is supported in the utterances' construction: both are 

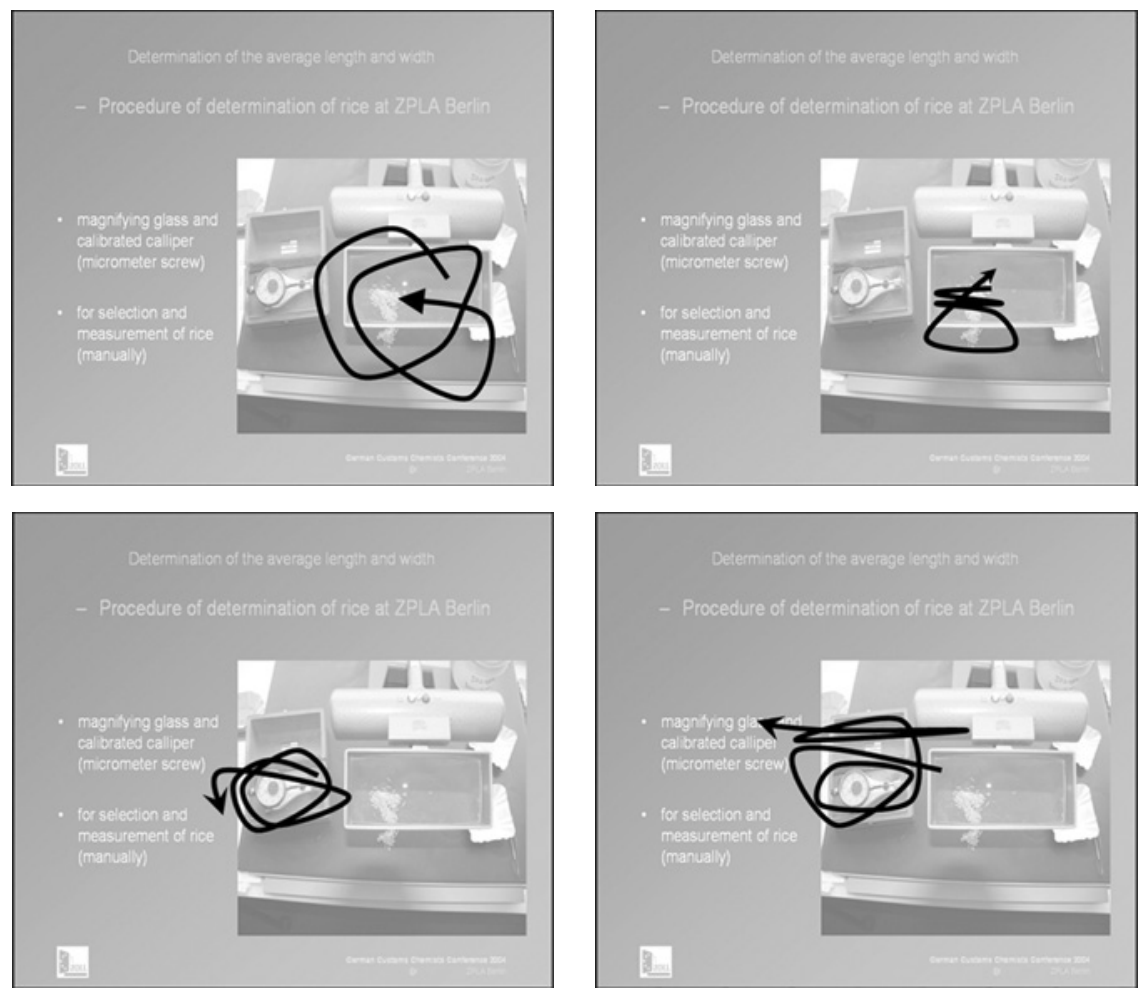

Figure 2 Laser pointer movements

introduced by an 'apostrophe', an address to the audience (in line 2 explicitly; in line 7 elliptically). Speaking, pointing, and the movements on the slide co-produce an understanding of the slide that identifies certain items and objects as well as their order. Performance here means more than just speaking and pointing; it also involves the visuality of the slide. Whereas in gesture studies such movements may be called 'iconographic', I would like to stress that rather than establishing meaning by the 'form' of the gestures, their impact is due to the fact that they exploit the spatial dimension of the visual device, thus maintaining an indicative character. In pointing, they circumscribe, encircle, underline or perform other movements which are deemed to be related to what is being shown. It is not by the means of the spatiality of the slide enacted in pointing that the objects talked about can be identified and ordered.

It would be utterly misleading to ascribe only a supportive role to these movements. As the next example will show, pointing gestures (again performed by means of a laser pointer) may be 'creative', that is, help to create their referent (Haviland, 1993: 27): 
1 (1.0) die Auswanderung von Lakedämonen aus dem Gefäß in das Gewebe $(1,0)$ The migration of lakedemons out of the vessels into the texture

2 ist=relativ=gut=untersucht, man weiß die Lakedämonen brauchen=zuerst $\mathrm{n}$ has=been=studied $=q u i t e$ well, one knows that the lakedemons first=need an

3 initialen Kontakt, (hat ä / geringe affine) Anlagerung; initial contact, (has a reduced affine) adaption;

4 des Rollen verstärkt dann den Kreisbewegung Kontakt=diese=feste=Anlagerung rolling motions then support the circular movements contact=this=fixed

$5 \longdiv { \overline { \text { wandert dann raus; } } }$ und wird sehr viel über die Moleküle in adaption then migrates; and will then via the molecules it will

6 Interaktion von Lakedämonen mit Europolzellen steuern control the interaction of lakedemons with the Europol-cells

7 und sie=ham=sich (jedoch viele) die Frage gestellt and=many of you may have asked...

This life-science presentation is held in front of an audience of about 50 people at a high profile conference. The speaker turns to the screen while leaving a pause $(1.0)$ - as he had done before in his speech quite frequently. The new slide he refers to in this text opens a new topic which is identified by the pseudonym 'lakedemons' (a bio-chemical structure analysed by his research group). Introduction of a new topic is accompanied by the speaker's discursive gestures illustrating the direction of the movements of these 'lakedemons' ('aus'
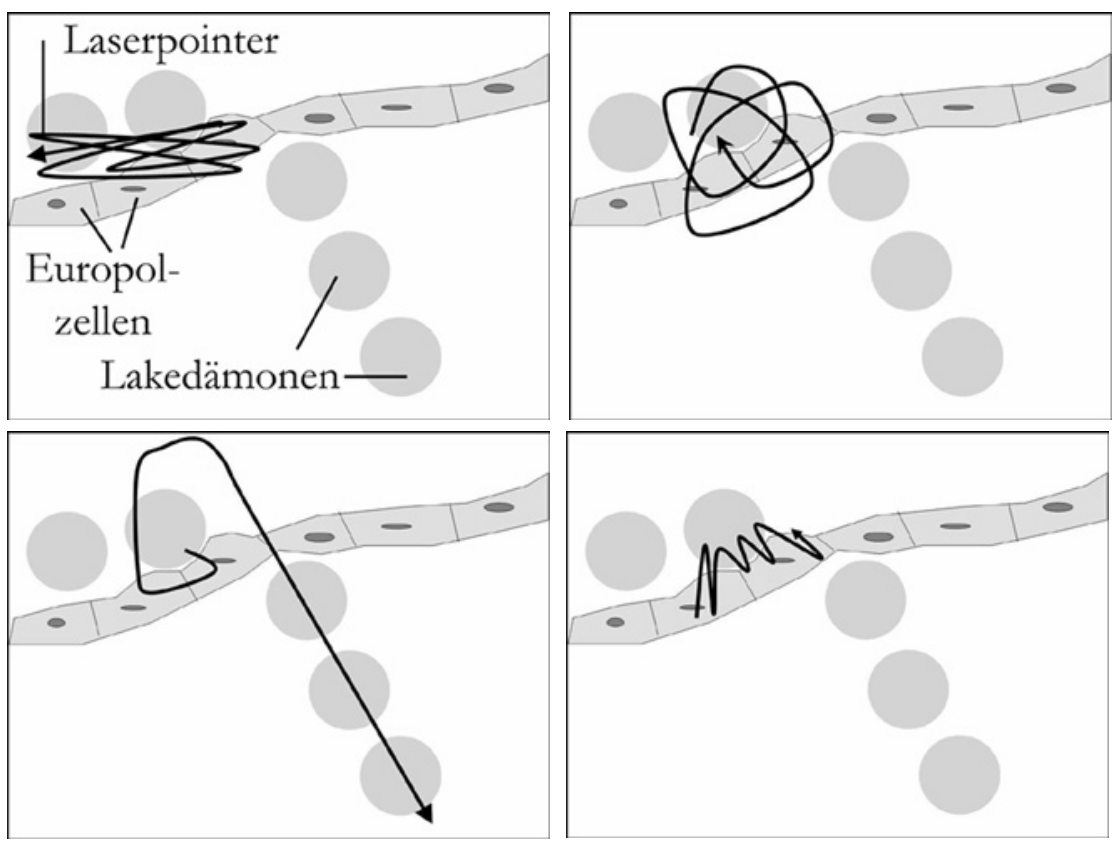

Figure 3 Laser pointer movements and body orientation 
or 'out', 'in' or 'in', line 1f) by two gestures of the hand turning outwards and turning inwards. As the double lines (lines 3,4,5,6) indicate, several times he points with the laser pointer at the diagram on the screen. Let us look at the ways he points at the screen in detail.

As can be seen in Figure 3, he not only points at the 'lakedemons' which are represented by little circles on the slide; he also moves the pointer in different ways throughout the slides. In relating these movements to what he is speaking about, it becomes clear that these pointing movements are quite meaningful: the 'initial contact' (line 3 ) of these bio-chemical structures with the 'Europol-cells' is underlined by a wave-like movement, their 'rolling' by a circular movement (line 4), their 'migration' by sudden straight movements (line 5), and their interaction by loop-shaped movements (lines 5ff). His movements seem to mimic the movements of these microscopic objects, again by exploiting the spatiality of the visual device. In doing this, they not only 'illustrate' what is being said or shown. Obviously, the difference between these movements corresponds to different parts of the talk ('first', 'then', 'will then'). But even more, while the slide represents a static view of various objects, these movements turn the static elements and the parts of the talk into a dynamic process. What appears as a simultaneous structure on the slide is thus turned into a temporal sequence of processes that are characterized by the movements.

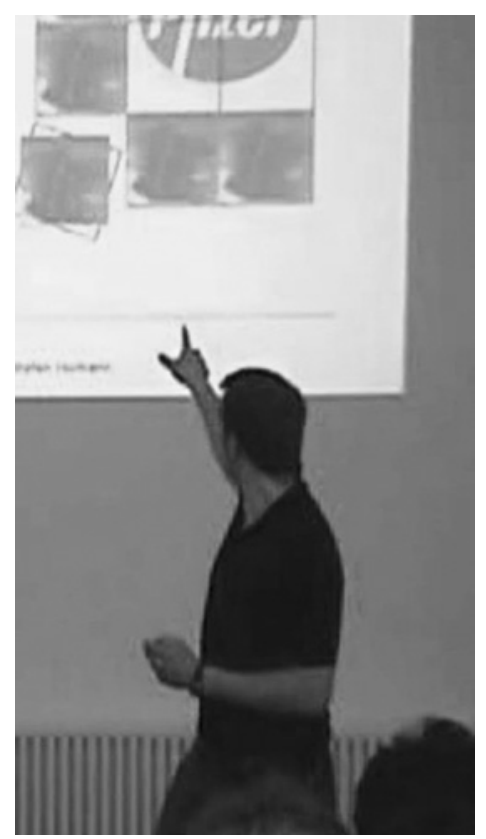

Figure 4 
Obviously, pointing does much more than just refer to something given. It relates to the spoken and the visible in a way that we can call performative. The meaning of what is being said lies neither in the spoken words nor the visuals only, but in fact in their interplay. At this point it is important to note that the meaning of presentations given to a live audience cannot be reduced to what is written on the slides only, as Tufte (2003) claims. For this reason, his criticism of powerpoint seems inadequate since he reduces the performance to its technical visuality only (a rather common way to construct 'information').

In fact, the meaning is accomplished by an interplay of spoken words, slides, and gestures, resulting in features which are not represented on the slide itself. ${ }^{10}$ Gesture, talk, and slide seem to elucidate one another respectively. However, in order to understand this interplay, we should not consider pointing, slides, and speech as separate categories; rather, they are all embodied activities. Given that we are focusing on the role of pointing in this article, we therefore have to look at the role of the body while pointing.

\section{Pointing, Body and Face Formation}

If one looks at gestures in a frame that extends beyond the 'gesture unit' (Kendon, 2004: 111), one observes that pointing involves the body to a degree that may belie our focus on the finger, the hand or the forearm. In many cases, pointing includes the orientation of the body, as illustrated in Figure 4. (I will restrict myself here to orientation of the body and exclude any references to body dislocations.)

While pointing to the screen, speakers turn their bodies in different ways. This turning of the body cannot be explained causally by the technology. In fact, the body would be able to point into the rays projected by the beamer so that the shadow may serve as a two-dimensional indicator, so to speak. However, this is hardly ever done. Instead, speakers usually turn their bodies in a three-dimensional way, thus highlighting the importance of spatiality. Turning to the screen by pointing, however, is an essential feature of powerpoint performances. Whereas in classical oratory speakers would turn their attention to the audience and, if the texts were read, to the manuscript, here the speakers turn away from the audience. This turn may take on various forms: speakers may turn around, briefly exhibiting their back to the audience; if they sit in front of a notebook computer, they may only slightly turn away, hinting at a turn to the screen rather than really pointing; in many cases, however, pointing is combined with a turn that positions the front of the body somewhere between the audience and the screen, as can be seen in Figure $5 .{ }^{11}$

In order to understand the meaning established by positioning the body between audience and screen, it may be helpful to turn to a similar orientation that we are familiar with in the performance of dialogical settings: the constellation of persons during face-to-face conversations. Kendon (1990) has labelled this positioning in face-to-face interactions 'face formation'. He stresses that 


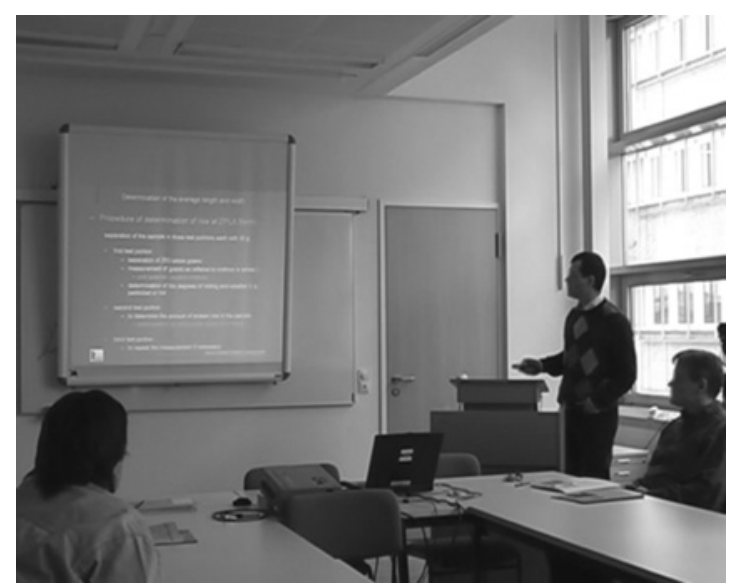

\section{Figure 5}

this formation indicates the kind of attention communication partners pay each other in interaction. Two actors would confront one another face-to-face. If the number of interaction partners increased, they would tend to stand in such a way that their bodies formed a circle in which each person had visible access to the others' faces. Changes within the interaction would affect the 'circle' which has to be understood as a dynamic structure. The face-formation indicates both 'addressability' and the actors' attentiveness to the communication.

Looking at the face formation, it appears that the powerpoint presentation differs from other forms of speech: the presentation is not just a two-sided relation between a speaker, impersonating a text, and an audience, as Goffman (1981) has shown for the lecture. Rather, the presentation is a relation between three elements in which the screen and the slide appear in the position of a third party in an interaction. This extension of a twofold into a threefold relation is underscored by what may be called the de-centring of the speaker. Whereas screens are often located in the centre of one wall of the room, the podium is moved to the side; moreover, the rooms are often dimmed to such a degree that it is not easy to see (or video) the speaker clearly. Often the 'stage' is centred around the screen. Within this triangular relation, the turning of the body not only supports pointing at the slide. It also helps to structure the attention of the listeners and of the speaker, since turning towards the screen may be used as a mnemotechnic device of the speaker in 'fresh' talk. Indeed, speakers from time to time may turn to the slide in such a way as to indicate the relevance of what is being said to what is being shown at certain points of their speech. Also in this respect even inexperienced speakers exhibit a refined sense of coordination between these two aspects.

This middle orientation between screen and audience can be maintained for longer stretches of time, and since the face itself may switch between screen and audience while the body is turned to and fro, we should note that the face as well 
as the body position may fulfil this function. At this point we should stress that the moving body obviously functions as a pivot in that it exhibits and steers attention. ${ }^{12}$ By pivot I mean that it is the body that is the most flexible element in the structuring of attention: although speech and slides may change, their position in space does not change. The body employs pointing and other gestures, the turning of the face and its reorientation as well as its movement within the space of audience and screen. Thus powerpoint presentations are not just performances. By virtue of the pivotal role of the body they are forms of 'immediate communication' (Knoblauch, 2001), that is to say, 'live performances'.

\section{Second Degree Pointing}

As mentioned above, pointing may be realized by changing the body or face orientation from a frontal to a lateral position, thereby drawing attention to the screen. Of course this change in body and face orientation cannot be called a gesture. Nevertheless, it somehow performs the function of pointing, for the body draws the audience's attention from the speaker to the screen. This function of drawing attention to the screen during the speech is not only realized by pointing. In fact, there are a number of presentations in which speakers can hardly point at all since they sit in a fixed position vis-a-vis the audience, so that turning around would disrupt the speech. In other cases, speakers may be positioned at one end of the room and the screen at the other, so that pointing does not make sense since the audience cannot closely monitor the speaker's body. ${ }^{13}$

The function of pointing as drawing attention to the screen (or slide) in a specific way does not even require an additional bodily activity. It may be produced in more subtle ways, as illustrated in the following case:

$1 \quad(3.0)<$ leises Räuspern> dann gibt es verschiedene

(3.0) (clearing the throat) then there are diverse

2 Entwicklungspfade, das ist auch äh unter soziologischen pathways of development, that are also er sociologically

3 Gesichtspunkten natürlich $\mathrm{n}$ interessantes-

of course a quite interesting

4 äh ne sehr intressante Frage welche Entwicklungspfade

er a very interesting question which pathways of development

5 von Pionieren sind eigentlich erfolgsversprechend

of pioneers prove to be promising

6 und welche (-) verlaufen im Sand. (1.7)

and which ones peter out. (1.7)

The speaker starts with a new slide and also a new topic (line 1): 'pathways of development' (in urban planning). He corrects himself before finishing a sentence (line 3); while restarting the sentence he briefly turns to the slide without pointing, yet returns to his original position in which he confronts the audience. Nevertheless, the reference to the slide becomes quite clear on, as it were, formal grounds, for the duality of his grammatical construction which forms a 

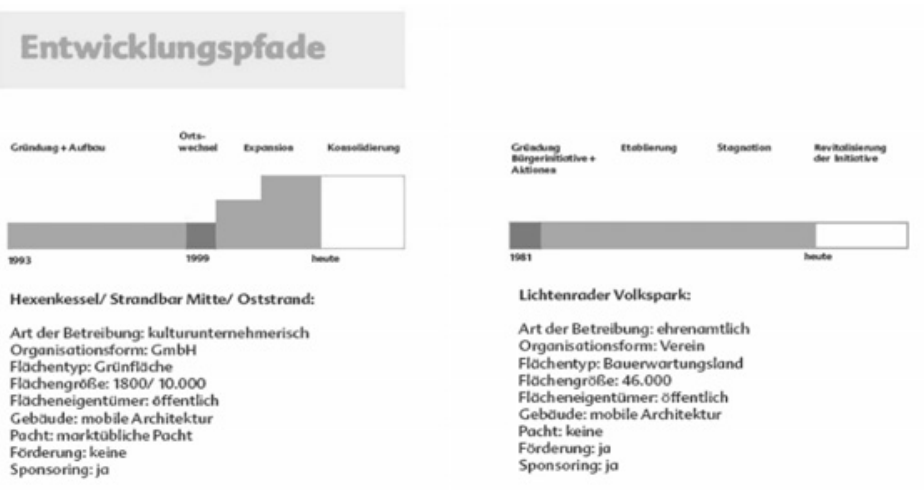

Figure 6

contrast (which are 'promising' [line 5] - which 'peter out' [line 6]) corresponds to the duality displayed by the graphical structure of the slide.

Like the previous case, text and slide are in a way paralleling one another by exhibiting a dual structure. Moreover, they also entail a recognition marker, a word that is part of the spoken text and at the same time represented on the slide, in this case 'pathways of development' ['Entwicklungspfade'] (see Figure 6). The rest of the slide seems of no real importance since it could not be perceived by the audience, nor does it figure in the speaker's talk. The slide is only relevant inasmuch as it graphically supports the duality of the structure of talk. Note again that the specific text on the slide - the subject of Tufte's analysis of powerpoint - is of no decisive importance for the understanding of the presentation. Rather, it is the spoken text in combination with certain elements of the slide which are indicated here in this indirect way of paralleling the dual structure. In fact, there are other formal procedures by which such paralleling may be accomplished: speakers may use phoric means, such as anaphora, cataphora or reflexive pronouns; they may parallel whole sentences (or slightly reformulate them); they may allude to contrasts, oppositions and itemizations ('first', 'second', 'then',); finally, they may use topicalization and items almost like a catchline.

Although paralleling establishes a reference between the spoken and the visual without deixis, it cannot be understood as pointing. There is no bodily gesture, and it does not even need a change in body formation. Rather, showing or demonstrating exhibits a similar circular structure, as does this kind of pointing: what is being said becomes evident by being seen, and what is seen is determined by being said. Thus the representational meaning of the slides is turned into a performative meaning in an almost circular way.

The parallelization of spoken language and slides requires substantial technical equipment. The slides that are designed on the notebook computer by employing the software (and this is what the software was originally designed 
for) have to be projected onto the screen (or the wall) by a beamer so as to accompany the speech. Even if they are not being pointed at, the slides are still 'shown' in a technical sense. This 'showing' may not be considered a gesture, yet it is accomplished by the technical constellation which is used by speakers when giving presentations. Presentations not only consist of text, speaker, and audience; they also consist of the slides shown on the screen and pointed at in such a way as to almost constitute another 'face' or element of interaction; moreover, they also involve a notebook and a beamer. In this sense, the technical constellation may be seen as a kind of institutionalization of pointing. ${ }^{14}$ This means that, insofar as they use such equipment, whatever speakers say may be understood as relating to whatever they show. (As with any institutionalized form, this general understanding is being specified by the various forms of pointing demonstrated here.) This assumption is supported by the recurrent deviant cases of presentations that occur when the technology fails: to the degree that speakers have produced slides beforehand, they seem to be unable to talk about what they want to talk about if they cannot show what they want to show - or they must switch genres. Quite frequently, the failure of technology leads to activities that may be seen as interruptions of the 'front stage' performance, to talk that occurs out of the frame (Goffman, 1981), and to repair work that reconstitutes the social division of labour that is being institutionalized in the technology: people who help to work on the software, the computer hardware, or the beamer. (Unsurprisingly, the more formal the occasion, the better provision there is for this division of labour.) Yet, when the technology works, pointing is also being performed by the technology itself - a fact the very name of 'powerpoint' accounts for. In other words, the technology and its product, the slide on the screen, have also to be considered as active elements in the performance of powerpoint.

\section{The Performance of Knowledge}

The powerpoint presentation and its visual relatives (presentations with diapositives and overhead projectors) differ from oral non-visual speech by the very fact that there is something that can be pointed at. Considering this difference from conventional talks, it is no surprise that 'presentation' has become a new label for this genre of speech. As a genre of oratory, presentations are defined as speech given by an embodied speaker, in the presence of an audience, employing a visual technical aid. One of the crucial features of presentations is that speakers can show something, with pointing being the most characteristic gesture. As has become clear, pointing consists of a bodily activity establishing a relation between screen (slide, technology), speech, and audience. Moreover, it turns out to be a gesture that allows us to draw attention to, and to select, what is relevant. And in combination with speech it even succeeds quite regularly in creating new meanings that are not represented either in the words spoken or on the slide pointed at. As already mentioned, this observation throws new light 
on the well-known criticism of presentations by Tufte. His observation of the impoverishment and fragmentation of information through powerpoint slides and their structures is based on one particular and, one may say, unduly isolated element of presentations, namely the slides. Tufte's critique ignores the fact that presentations cannot be reduced to the slides, ${ }^{15}$ but are typically supported by speech (which may differ from the text on the slides) and by pointing (as well as other bodily aspects). What is relevant to the communication process cannot be reduced to or 'decoded' from the slides but is part of the presentation as performance. (This criticism also demonstrates that the notion of information used by Tufte is inadequate to cover what happens in powerpoint presentations.)

Powerpoint is not the first (and by far not the only) visual medium of presentation. There are other media that have been used before in scientific or business communication as well as in education. However, powerpoint has several distinguishing features. It is characterized by the fact that it integrates the visual media into an overall structure of speech (even by the means of a half-automated 'auto content manager'). Although the genre is sometimes used for entertainment (as in 'powerpoint Karaoke') and church services, Tufte may be right in assuming that the general function of this genre has something to do with information or, if we want to avoid the reductionist consequences of this notion, knowledge transmission (in rhetorical terms docere). It may be for this reason that the performance of powerpoint in some way resembles scientific practices of visualization and visual presentation. Whereas many scientific powerpoint presentations are still close to the visually supported scientific lecture, most presentations in other fields (and also a significant number in science) take on features that are rather specific to powerpoint presentations. Whereas in science visualizations in presentations represent and relate to practices of the visualization of an 'empirical reality' (for example, the laboratory with all its instruments of visualization) (Amann and Knorr-Cetina, 1988; Lynch and Woolgar, 1990), the typical powerpoint slide does not claim to represent anything but aims to illustrate what is being said. It represents that and also how the producer has prepared the presentation, the inventio, as classical rhetoric would call it. With powerpoint the inventio not only includes the speech but also the design of slides. And in this process it is not the reference to visualizations in data measurement, as in science, but the design of the presentation that plays a role: design options are offered and patterned by the software (e.g. graphic programmes) or downloaded from other media such as email and the internet (e.g. pictures, diagrams). In this way, the projected slide uses the visual repertory that is accessible by the computer as a medium. As Pötzsch and Schnettler (2006) show, these visual forms are still quite standardized (i.e. bullet points, pre-given diagram types, and so on).

The standardization that results from the technological support is apparently compensated for by the apparent 'freshness' of the talk and the bodily performance. In fact, the most typical powerpoint presentation avoids using written texts and prefers what may be called 'quasi-fresh talk'. As opposed to 
'truly' fresh talk, this quasi-fresh talk is defined by the fact that it relates to the text shown on the slides. (Indeed, the majority of slides do not consist of visual representations but of words. $)^{16}$ The dominance of the bullet-point type text order results in patterns of speaking that resemble chains of commentaries and remarks more than chains of arguments (Schnettler, 2006). As we have seen, however, the spoken text does not stand for itself but is related to the visual by way of performance, that is, pointing. In this respect, presentations can be said to exhibit a circular structure that is most explicit in the case of pointing: what is being said refers to what is being pointed at (or shown), and what is being pointed at (or shown) refers to what is being said.

Nevertheless it would be mistaken to conclude that knowledge presented in this way is just a 'simulation' (Baudrillard, 1983), for the presentation is not caught in the circularity (or the redundancy) of textual and visual signs. Instead, it is the performance that produces meaning situationally. As stated before, the performativity does not lie simply in the words and speech acts but extends to pointing and bodily conduct. Pointing as performance produces the 'surplus' of meaning that allows us to understand what goes on. What is talked about in the fluidity of time is being transformed not only into something visual but also something embodied and spatial. It is the situational and sequentially most sensitive bodily performance that connects speech and pictures in such a way that they make sense - and obviously much more sense than they would do on their own (as Tufte demonstrates). As has been shown with respect to pointing, the situational character of this performance is not restricted to pointing and face formation; it also includes the projection technology and the spatial architecture (walls, screens, locations of speakers and audience) that allow for 'pointing of the second degree'. ${ }^{17}$ Despite the role of technology, we cannot talk of 'mediatized performances', such as live concerts that are circulated on videotapes or television (Auslander, 1999: 5). In order to characterize the mixture of technological mediatization (of text and visual aids) and live performance (speech, body, audience, and other contextual elements) typical of powerpoint, we should talk of hybrid performances that link a text and visual deck prepared in advance with fresh talk that is enacted situationally by performative means.

Invoking the restricting and enabling features of the material environment and, particularly, technologies, the work of Latour (1993) questions whether one may still talk about human actors alone doing the performance. With respect to powerpoint presentations, one may indeed concede that it is not only the speaker who is acting in this situation. However, there is no reason to consider technology (or, for that matter, spatial architecture) as non-human agency. In fact, inasmuch as performance is a cultural and social accomplishment, it exceeds the logic of individual action as does any social institution (by definition). It is exactly for this reason that I treat performance as something that exhibits an order of its own. At this level, the question 'who is the actor?' would miss the point of the argument. ${ }^{18}$

It is not so much agency but knowledge that is at issue in these presentations. That is not to say that knowledge is a kind of 'underlying' substance 
inherent in the presentation. Instead, the presentation as a form contributes to the impression that what is at stake here is knowledge. In other words, powerpoint presentations employ a pattern of culturally conventionalized elements of 'knowledge transmission' - be that knowledge about a product (as in the economy), about procedures (as in bureaucracy or technology), or anything else that is considered legitimate knowledge (i.e. something that is considered to be the subject of socially recognized knowledge transmission).

This feature of powerpoint may be related to its increasing social and cultural significance. Given the scale of dissemination of this technology, one should note the cultural extension of knowledge transmission by means of this genre. Whereas knowledge transmission typically used to be restricted to science and educational institutions (schools, universities and professional training departments), the success of powerpoint in business, administration and the military demonstrates the growing importance of knowledge transmission in contemporary society - an importance that is frequently caught by the notion of 'knowledge society' (Webster, 1995; Knoblauch, 2005). (But since the notion of 'information' turned out to be inadequate, this also holds true for the notion of 'information society'.) Nowadays, powerpoint presentations have become a routine activity in most functional systems of societies, to such a degree that their preparation, performance, or reception covers a substantial amount of working hours of an increasing number of people (Yates and Orlikowski, forthcoming).

With respect to this institutional aspect of powerpoint presentations, ${ }^{19}$ the genre has developed in an interesting way. Whereas visual support of speech had been common in education and science for a long time, the more recent technical sophistication of visualized presentation is due to business communication and management. ${ }^{20}$ It seems as if the development of scientific management has facilitated the adoption of scientific forms of communication in management and business. After slide presentations by overhead, flip charts, and, later, powerpoint first became familiar in economic institutions, they 'migrated' into science, education and administrations. (The very fact that 'presentation' has been kept as a label for the genre may still indicate its economic origin.) This economic origin of, one might say, a paradigmatic genre of the knowledge society is an observation that deserves to be highlighted. Most theories of the knowledge society assume that this type of society is characterized by the dissemination of scientific knowledge into other institutional spheres (Bell, 1973; Stehr, 1994), although if one considers communication as a form of knowledge, one could instead argue that it is the other way round, and that economic forms of communication have impacts on scientific knowledge. Yet it would be simplistic to conclude that the 'knowledge' transmitted by powerpoint therefore must be, necessarily, 'economic' in nature, and to go on to a cultural critique of the 'capitalistic contamination' of knowledge, for this would assume that knowledge can be substantially defined and distinguished by its different substances into 'economic', 'scientific' and so on. 


\section{Conclusion}

The dissemination of powerpoint hints at a form of de-specialization and a type of dissolution of the social and institutional boundaries of knowledge that also characterizes other computer-mediated communication by internet or email. The fact that the very same form of communication can be used in diverse institutional settings speaks for the increasing similarity of the knowledge transmitted in these forms. The dissolution of the knowledge boundaries known hitherto becomes visible in the fact that whatever knowledge is performed by powerpoint, the form is unaffected. In all instances, however, the knowledge transmission is dependent on the fact that it is being performed. The reasons for the performance of knowledge can be found in the very processes that contribute to its success: the dissolution of institutional boundaries of knowledge (that is, organized by discipline or profession) and, even more, the increasing de-institutionalization and de-contextualization of knowledge communication by mediation technologies, a process that in turn demands a re-contextualization of knowledge. Performance is, so to speak, situational repair work for the standardization of communication processes in a 'knowledge society' that depends increasingly on its knowledge being performed.

\section{Notes}

1 The research project is supported by the German Research Foundation (DFG); its official title is 'The Performance of Visually Supported Presentations: GenreAnalytic Studies of a Communicative Form Paradigmatic for Knowledge Society'. PowerPoint is only one brand of software among others; however, as it has become synonymous with the sorts of presentations that we have studied, we spell it - powerpoint - in a manner that is not identical with the trade name.

2 There is no doubt that presentation software technologies yield textual genres other than the presentation. Thus powerpoint slides may be distributed by email or they may be presented within the frame of dialogical conversations. Despite the fact that these forms exist in enormous numbers - there are about 14 million presentations available on the net - they should be considered rather as 'corollaries', that is, as forms derived from the crucial and major form of presentation that still constitutes their reference point (Yates and Orlikowski, forthcoming). For reasons to be explained in this article, these derived forms did not succeed in substituting for the presentation as the distinctive and essential form.

3 The question of whether these technologies may be considered as actors in their own right - a question prompted by the writings of Latour (1993) - is being pursued by another part of this research project that analyses in particular the very frequent technological failures during powerpoint presentations. See Schnettler and Tuma (forthcoming).

4 In the words of Hanks (1990: 5): 'the term deictic in traditional grammar designates (roughly) linguistic elements which specify the identity or placement in space or time of individuated objects relative to the participants in a verbal 
interaction. English 'this', for instance, in one of its central uses, identifies a specific object given in the immediate spatial proximity of the speaker who utters the form'.

5 As Hindmarsh and Heath (2000: 1857) show, interaction is the prerequisite which makes that to which one points a relevant object.

6 In one of the most encompassing studies of pointing, Kendon (2004: 199-224) distinguishes different forms of pointing by identifying various positions of the hand. In its most common form, pointing may be done by the extended index finger. Pointing may also be done by using the open hand. The hand may be opened in an upward direction or in a downward direction, palms may be turned to the pointing subject. In rare cases, pointing may also be done with the thumb. On the basis of these formal distinctions, Kendon then determines different functions of meanings of pointing. Thus pointing with the open hand would occur when the actor attempts to comment on an object. Pointing with the hand turned outside would be used when the object related to is being highlighted. Other forms of pointing, he suggests, are also related to certain 'semantic themes'.

7 Transcription conventions are explained at the end of the text, in the appendix.

8 Discursive gestures are defined as accompanying the text, for example in marking the rhythmic structure. See Müller (1998).

9 One may doubt if the pointing below still represents 'pure' deictical gestures since they use iconographic elements. On the other hand, the laser pointer is in itself the purest case of pointing, since the iconographic elements are reduced almost perfectly (as opposed to an 'arrow' that itself is iconographic). The variety of forms for pointing, such as arrows, for printed texts is described by Storrer and Wyss (2003).

10 Schnettler (2006: 157) calls this interplay 'orchestration'.

11 It should be added that in this respect there are differences within presentations by single speakers as well as between speakers, so that this feature would allow for a typification of speakers that, however, cannot be pursued here.

12 In their analysis of pointing at pictures, Pozzer-Ardenghi and Roth (2005: 277) remark that 'gestures and body orientation constitute important resources for establishing coherence during lectures that allow audiences to appropriately connect photographs and speech'.

13 It is interesting that in this case the audience is - as in a tennis match - continuously changing the direction of its gaze as if trying to link speaker and screen which are spatially separated.

14 The comparison between technology and institution is made explicit by Rammert (2006).

15 See the notion of corollaries of presentations discussed by Yates and Orlikowksi (forthcoming).

16 There are, of course, disparities with respect to institutional and disciplinary fields, but almost $40 \%$ of the slides analysed are text only and another $40 \%$ are text and graphics. See Pötzsch and Schnettler (2006).

17 I have analysed the spatial settings and their 'effects' on the performances in another article that will be published shortly in German (Knoblauch, forthcoming).

18 That is not to say that it is generally unimportant. In hermeneutically trying to understand single sequences, we do of course assume actors who are to be understood; the structures, however, resulting from these interpretations (such as genres) are taken to transcend the level of actors. 
19 This level of analysis is called the 'outer structure' in genre analysis. One must stress that this level is not 'external' to the genres but is rather a constitutive element of their definition. See Knoblauch and Luckmann (2004).

20 The first diagrams produced on the basis of numeric numbers were utilized by representatives of Systemic Management in Ergonomics. The first introductory textbooks about producing diagrams appeared around 1914; at the same time, diagrams were used in presentations. By 1920, DuPont had created special rooms to show diagrams ('chart rooms'). This DuPont method was frequently copied, but it was only in the second half of the 20th century that visual technologies supporting speeches were increasingly used. The 1970s saw the invention of the overhead projector and a rapid rise in its sales, these doubling between 1975 and 1985. Since the late 1980s, PCs have grown in importance insofar as the production of diagrams is concerned. Thus 'Presenter', the predecessor of PowerPoint, was created to support the design of slides. It was only then that the new software slowly started to be used also as a part of presentations. See Yates and Orlokowski (forthcoming).

\section{References}

Alexander, J.C., Giesen, B. and Mast, J.L. (eds) (2006) Social Performance, Symbolic Action, Cultural Pragmatics and Ritual. Cambridge: Cambridge University Press.

Amann, K. and Knorr-Cetina, K. (1988) 'The Fixation of Visual Evidence', Human Studies 11(2/3): 133-69.

Auslander, P. (1999) Liveness: Performance in a Mediatized Culture. London: Routledge.

Baudrillard, J. (1983) Simulations. New York: Semiotext(e).

Bauman, R. and Briggs, C.L. (1990) 'Poetics and Performance as Critical Perspectives on Language and Social Life', American Review of Anthropology 19: 59-88.

Bell, D. (1973) The Coming of Post-Industrial Society. New York: Basic Books.

Butler, J. (1988) 'Performative Acts and Gender Constitution: An Essay in Phenomenology and Feminist Theory', Theatre Journal 40(4): 519-31.

Goffman, E. (1981) 'The Lecture', in E. Goffman Forms of Talk, pp. 160-96. Oxford: Blackwell.

Habermas, J. (1981) Theorie des kommunikativen Handelns. Frankfurt am Main: Suhrkamp.

Hanks, W.F. (1990) Referential Practice: Language and Lived Space among the Maya. Chicago: University of Chicago Press.

Haviland, J.B. (1993) 'Anchoring, Iconicity, and Orientation in Guugu Yimithirr Pointing Gestures', Journal of Linguistic Anthropology 3(1): 3-45.

Heath, C. and Hindmarsh, J. (2002) 'Analysing Interaction: Video, Ethnography and Situated Conduct', in M. Tim (ed.) Qualitative Research in Action, pp. 99-121. London: Sage.

Hindmarsh, J. and Heath, C. (2000) 'Embodied Reference: A Study of Deixis in Workplace Interaction', Journal of Pragmatics 32(2): 1855-78. 
Hymes, D. (1974) Foundations in Sociolinguistics: An Ethnographic Perspective. Philadelphia: University of Philadelphia Press.

Kendon, A. (1990) 'Spatial Organization in Social Encounters: the F-formation System', in A. Kendon Conducting Interaction: Patterns of Behavior in Focused Encounters, pp. 209-38. Cambridge: Cambridge University Press.

Kendon, A. (2004) Gesture: Visible Action as Utterance. Cambridge: Cambridge University Press.

Knoblauch, H. (2001) 'Communication, Contexts and Culture: A Communicative Constructivist Approach to Intercultural Communication', in A. di Luzio et al. (eds) Culture in Communication: Analyses of Intercultural Situations, pp. 3-33. Amsterdam and Philadelphia: John Benjamins.

Knoblauch, H. (2005) Wissenssoziologie. [Sociology of Knowledge] Konstanz: UTB.

Knoblauch, H. (2006) 'Videography. Focused Ethnography and Video-Analysis', in: H. Knoblauch et al. (eds) Video Analysis - Methodology and Methods: Qualitative Audiovisual Data Analysis in Sociology, pp. 69-83. Frankfurt am Main and New York: Lang.

Knoblauch, H. (forthcoming) 'Wissen Live: Sitzordnung, Performanz und Powerpoint', in H. Willems (ed.): Theatralisierungen und Enttheatralisierungen in der Gegenwartsgesellschaft. Wiesbaden: VS.

Knoblauch, H. and Günthner, S. (1995) 'Culturally Patterned Speaking Practices the Analysis of Communicative Genres', Pragmatics 5(1): 1-32.

Knoblauch, H. and Luckmann, T. (2004) 'Genre Analysis', in: U. Flick et al. (eds.) A Companion to Qualitative Research, pp. 303-7. London: Sage.

Latour, B. (1993): We Have Never Been Modern. New York: Prentice Hall.

Lynch, M. and Woolgar, S. (eds) (1990) Representation in Scientific Practice. Cambridge: Kluwer.

Müller, C. (1998) Redebegleitende Gesten: Kulturgeschichte - Theorie Sprachvergleich. Berlin: Arno Spitz.

Pötzsch, F.S. and Schnettler, B. (2006) 'Bürokraten des Wissens? "Denkstile" Computerunterstützter visueller Präsentationen', in W. Gebhard and R. Hitzler (eds) Nomaden, Vagabunden oder Flaneure? Wissensformen und Denkstile der Gegenwart, pp. 186-202. Wiesbaden: VS.

Pozzer-Ardenghi, L. and Roth, W.M. (2005) 'Photographs in Lectures: Gestures as Meaning-Making Resources', Linguistics and Education 15(3): 275-93.

Rammert, W. (2006) 'Die technische Konstruktion als Teil der gesellschaftlichen Konstruktion der Wirklichkeit', in D. Tänzler et al. (eds) Zur Kritik der Wissensgesellschaft, pp. 83-100. Konstanz: UVK.

Schnettler, B. (2006) 'Orchestrating Bullet Lists and Commentaries: A Video Performance Analysis of Computer Supported Presentations', in H. Knoblauch et al. (eds) Video Analysis: Methodology and Methods. Qualitative Audiovisual Data Analysis in Sociology, pp. 155-68. Frankfurt am Main and New York: Lang.

Schnettler, B. and Tuma, R. (forthcoming) 'Präsentationspannen: Die Rolle der Technik und deren Bewältigung', in B. Schnettler and H. Knoblauch (eds): Präsentationen: Formen der visuellen Kommunikation von Wissen, pp. 212-35. Konstanz: UVK.

Stehr, N. (1994) Knowledge Societies. London: Sage. 
Storrer, A. and Wyss, E.L. (2003) 'Pfeilzeichen: Formen und Funktionen in alten und neuen Medien', in U. Schmitz and H. Wenzel (eds) Wissen und neue Medien: Bilder und Zeichen von 800 bis 2000, pp. 159-95. Berlin: Erich Schmidt.

Tufte, Edward R. (2003) The Cognitive Style of Powerpoint. Cheshire, CT: Graphics Press.

Webster, F. (1995) Theories of the Information Society. London: Blackwell.

Yates, J. and Orlikowski, W. (forthcoming) 'The Powerpoint Presentation and Its Corollaries: How Genres Shape Communicative Action in Organizations', in M. Zachry and C. Thralls (eds) Communicative Practices in Workplaces and the Professions: Cultural Perspectives on the Regulation of Discourse and Organizations. Amityville, NY: Baywood Publishing.

\section{Appendix: transcription conventions}

\begin{tabular}{|c|c|}
\hline , ? & slightly / strongly rising intonation \\
\hline : . & slightly / strongly falling intonation \\
\hline (.) & short pause \\
\hline$(5.0)$ & long pause (in seconds) \\
\hline dam- & unfinished utterance \\
\hline$=$ & quick link \\
\hline ne::: & extended \\
\hline$*$ & stressed \\
\hline$\circ$ & calm \\
\hline LAUT & loud \\
\hline (wann) & uncertain transcription \\
\hline$(\quad)$ & not identified utterance \\
\hline double & ines: accompanied by pointing gestures \\
\hline
\end{tabular}

Note: for all proper names (people, cities, geographic identifications and scientific notions) pseudonyms have been used in the transcript 


\section{Hubert Knoblauch}

Hubert Knoblauch is Professor of General Sociology at the Technical University of Berlin. He has been Chair of the Research Network Qualitative Methods and is now on the Board of the Research Network on Sociology of Culture in the European Sociological Association. He is Elected Referee of the German Research Association (DFG) for Empirical Social Research, Referee of the European Science Foundation and on the Steering Committee of the ESF-Project EUROQUAL (Qualitative Research in Europe). His research focuses on religion, communication, knowledge, and qualitative methods, particularly video analysis. Recent publications include Verbal Art Across Cultures: The Aesthetic and Proto-Aesthetic Forms of Communication (edited, with Helga Kotthoff) Tübingen: Gunter Narr (200 I); Qualitative Methods in Europe: The Variety of Social Research (edited, with Uwe Flick and Christoph Maeder) FQS 6/3 (2005), see http://www.qualitative-research.net/fqs-texte/3-05/05-3-34-e.htm; Wissenssoziologie [Sociology of Knowledge] Konstanz: UTB (2005); and Video-Analysis: Methodology and Methods (edited, with Bernt Schnettler) Berlin: Lang (2006).

Address: Technical University of Berlin-Franklinstrasse 28/29-D- I0587, Berlin, Germany. Email: Hubert.Knoblauch@tu-berlin.de 